8. Blake-Mortimer J, Gore-Felton C, Kimerling R, et al. Improving the Quality and Quantity of Life Among Patients With Cancer-A review of the effectiveness of group psychotherapy. European Journal of Cancer October 1999; 35(11): 1581-6.

9. Brigden M, McKenzie M. Treating Cancer Patients. Practical monitoring and management of therapy related complications. Canadian Family Physician November 2000; 46: 2258-68.

10. Goel V, Olivotto I, Hislop TG, Sawka C, Coldman A, Holowaty EJ. Patterns of initial management of node-negative breast cancer in two Canadian provinces. British ColumbiaOntario Working Group. CMAJ January 1997;156(1):25-35.
11. Epidemiology and Surveillance Branch. NSW Clinical Cancer Data Collection for Outcomes and Quality-Data DictionaryVersion 1. Sydney: NSW Department of Health, 2001.

12. Business case for the acquisition of integrated information systems and supporting infrastructure. Sydney: NSW Department of Health, October 1998.

13. Radiation oncology information, management and technology strategic plan. Sydney: NSW Department of Health, October 1998.

14. NHMRC Draft Guidelines Under Section 95A of the Privacy Act. www.nhmrc.gov.au/ethics/dftguid.htm. $\mathbb{F}$

\title{
CANCER PATIENTS' SUPPORTIVE CARE NEEDS: STRATEGIES FOR ASSESSMENT AND INTERVENTION
}

\section{Afaf Girgis and Louise Burton \\ The Cancer Council NSW}

This article describes some of the work undertaken over the last decade by The Cancer Council NSW-through the Cancer Education Research Program (CERP) and the Cancer Services Unit- to measure the supportive care needs of cancer patients, and identify effective strategies for attending to these needs as part of routine clinical practice.

Cancer is a major cause of morbidity and mortality throughout the world, with nine million people newly diagnosed each year and five million people dying from the disease. ${ }^{1}$ In Australia, cancer is the second most common cause of death, accounting for approximately one quarter of all deaths. ${ }^{2}$ Approximately 55,000 cases of cancer are diagnosed each year, the most common being cancers of the breast, prostate, colon-rectum, lung, and melanoma. Due in part to the focus on early detection and improved clinical management of cancer, five-year survival rates indicate that more people are now living with cancer, and for longer periods of time. ${ }^{1,3}$

Most cancer patients now undergo a combination of effective-but nonetheless traumatic - treatments such as the surgical removal of the cancer, radiotherapy, chemotherapy, and hormone therapies. Although these treatments have the potential to cure some cancers, and to prolong the lives of patients with other cancers, they are associated with a wide range of physical and psychosocial problems. The psychosocial morbidity experienced by cancer patients has been estimated using a number of different strategies including the assessment of quality of life; satisfaction with care; and, more recently, needs assessment. Quality of life research has indicated that the diagnosis and subsequent treatment of cancer impairs cancer patients' work and social activities, management of the home, family and other relationships, sleep patterns, and sexual activity. ${ }^{4-7}$ In addition, studies exploring the psychological sequelae of cancer have suggested that cancer patients experience clinically significant levels of anxiety and depression. ${ }^{5,7-13}$

Although both cancer specialists and patients may accept physical and psychosocial problems as an inevitable part of the disease and its treatment, ${ }^{14,15}$ these problems can have a substantial affect on cancer patients' compliance with their treatment and with outcomes. For example, it has been estimated that up to one-third of patients will abandon chemotherapy prematurely as a result of the physical and psychosocial symptoms, despite the potentially life-threatening consequences of such action. ${ }^{16}$ Therefore, it is important for cancer specialists to be aware of the prevalence of such problems among their cancer patients and to do their best to prevent them where possible or to address them when they occur.

The routine assessment of cancer patients' unmet needs in the clinical setting has the potential to quickly identify issues of concern for the patient, which can then be brought to the attention of the treatment team for appropriate intervention. In contrast to assessments of satisfaction and quality of life, needs assessments directly assess and identify specific issues for patients, as well as the perceived magnitude of those needs. In this context, 'needs' can be defined as the requirement of some action or resource that is necessary, desirable or useful to attain optimal wellbeing. ${ }^{17}$ Needs assessment enables individuals-and sub-groups of patients with higher levels of needs-to be identified and targeted with appropriate early interventions; and allows those aspects of health services that require improving to be identified and prioritised. ${ }^{18}$

Research on the needs of patients with cancer has identified high levels of unmet need and a difference in the types of unmet needs depending on the cancer population studied. For example, high levels of unmet need in the provision of information have been reported in studies with different types of cancer 
TABLE 1

THE 10 AREAS OF NEED, EXPERIENCED IN THE PREVIOUS MONTH, RANKED HIGHEST BY PATIENTS COMPLETING THE SUPPORTIVE CARE NEEDS SURVEY ACROSS ALL TREATMENT GROUPS AND CENTRES OF CARE

\begin{tabular}{|c|c|c|}
\hline moc & $\begin{array}{l}\text { sample } \\
\text { rting a } \\
\text {-high need }\end{array}$ & Domain \\
\hline Fears about the cancer spreading & 40 & Psychological \\
\hline Fears about the cancer returning & 39 & Psychological \\
\hline Concerns about the worries of those close to you & 38 & Psychological \\
\hline To be informed about the things you can do to help yourself to get well & 36 & Health system-information \\
\hline Lack of energy and tiredness & 33 & Physical-daily living \\
\hline Not being able to do the things you used to do & 33 & Physical-daily living \\
\hline Uncertainty about the future & 32 & Psychological \\
\hline $\begin{array}{l}\text { To be informed about the cancer which is under control or diminishing } \\
\text { (that is, remission) }\end{array}$ & 32 & Health system-information \\
\hline To be informed about your test results as soon as feasible & 31 & Health system-information \\
\hline Concerns about the ability of those close to you to cope with caring for you & 30 & Psychological \\
\hline
\end{tabular}

patients, ${ }^{19,20}$ with breast cancer patients ${ }^{21,22}$ and with melanoma patients. ${ }^{23}$ Other studies of patients undergoing treatment for cancer have reported high levels of physicaldaily living needs. ${ }^{24-28}$ Most recently, the largest published study describing the prevalence and predictors of unmet needs among cancer patients $(n=888)$ across NSW, using the Supportive Care Needs Survey, ${ }^{29}$ revealed that cancer patients continue to experience high levels of unmet needs across a range of domains, including: psychological support, health system and information, physical and daily living, patient care and support, and sexuality. In the survey, 59 items were presented with a stem question of 'In the last month, what was your level of need for help with', with response options: 'No need, not applicable', 'No need, satisfied', 'Low need', 'Moderate need' and 'High need'. As indicated in Table 1, the highest levels of need were found to be in the psychological domain, which accounted for half of the top 10 unmet needs identified in this study, with a further three items from the health system and information needs domain and two relating to their physical and daily living. The results of this state-wide survey also showed that subgroups of patients experienced different types of needs, with the predictors of reporting some unmet need for help varying according to the domain examined. ${ }^{30}$

The main purpose of assessing the physical symptoms and unmet needs of people diagnosed with cancer is the improvement of their care. However, such assessments can only result in improvement of care if: a) the team providing treatment is aware of the physical and psychosocial problems of individual patients; and b) strategies are available to address the issues raised by individual patients.

In an effort to improve the coordinated care of people with cancer, The Cancer Council NSW is planning a multifaceted collaborative initiative with cancer treatment centres and health services across the state. The aim of the proposed Cancer Services Quality Improvement program is to implement and evaluate a program to facilitate better psychosocial management of cancer patients by health services. It will consist of the following components:

- needs assessment: Based on methodology developed and trialed by CERP, all cancer patients attending the participating centres will complete a touchscreen computer survey in the waiting room, prior to their appointment with their oncologist, to assess their unmet needs, anxiety and depression and physical symptoms;

- clinician feedback: Research undertaken by CERP indicates that the awareness of oncologists of their individual patient's physical and psychosocial outcomes is less than optimal, thus limiting the opportunity for them to intervene to address their patient's needs. ${ }^{31}$ Hence, each individual patient's results will be printed immediately following their completion of the survey and provided to the clinician in a summary form. Those issues identified by their patient involving routine clinical management can be reviewed. Results of a pilot study of this feedback strategy indicates promising outcomes for patients, ${ }^{32}$

- multidisciplinary workshops: Treatment centres will clearly have different levels of access to services and personnel who are able to address individual patients' needs. It is therefore imperative that a tailored approach be taken to the provision of interventions. To identify appropriate clinical pathways and referral systems for patients with different psychological, social and living needs, a structured workshop will be conducted with the multidisciplinary team of each participating cancer treatment centre or health service. The workshop would ensure that there are effective management and referral processes in operation across the centre (to social workers, psychologists, cancer support groups, volunteers, etc). The Psychosocial 
Clinical Practice Guidelines: Information, support and counselling for women with breast cancer, endorsed by the National Health and Medical Research Council, will inform the provision of effective interventions to improve patients' psychosocial care $;^{33}$

- patient financial assistance scheme: The Cancer Council NSW may implement a financial assistance scheme to provide both no interest loans and (immediate, smaller) welfare grants to patients experiencing financial difficulties. This financial assistance scheme would be a referral point for cancer treatment centres;

- professional education: Further professional education and resources on survival rates and support topics will be provided, as requested by participating centres;

- benchmarking: CERP will analyse individual treatment centre data and provide summary reports for every 100 patients. Furthermore, comparative data for all centres combined will be provided to allow comparison of individual centre outcomes to outcomes for the whole group.

The coordinated process described above is currently being piloted and is one approach to ensure that cancer patients receive optimal psychosocial assessment and care during the management of their cancer.

\section{REFERENCES}

1. Koroltchouk V. Treatment in cancer control. Advances in national cancer control: managerial aspects (Jerry LM, Stjernsward J). Canada: World Health Organization Collaborating Centre for Cancer Control, 1994; 23-49.

2. Australian Institute of Health and Welfare. Australia's Health 1996: the fifth biennial health report of the Australian Institute of Health and Welfare. Canberra: AGPS, 1996.

3. South Australian Cancer Registry. Epidemiology of cancer in South Australia 1977-95. Adelaide: South Australian Health Commission, 1996.

4. Malone M, Harris AL, Luscombe DK. Assessment of the impact of cancer on work, recreation, home management and sleep using a general health status measure. J R Soc Med 1994; 87: 386-9.

5. Campora E, Nasco C, Vitullo M, Giudici S, Camoirano A, Repetto L, et al. The impact of chemotherapy on quality of life of breast cancer patients. J Chemother 1992; 4: 59-63.

6. Arzouman JMR, Dudas S, Ferrans CE, Holm K. Quality of life of patients with sarcoma postchemotherapy. Oncol Nurs Forum 1991;18: 1221-7.

7. Gilbar O. The quality of life of cancer patients who refuse chemotherapy. Soc Sci Med 1991; 32: 1337-40.

8. Aass N, Fossa SD, Dahl AA, Moe TJ. Prevalence of anxiety and depression in cancer patients seen at the Norwegian Radium Hospital. Eur J Cancer 1997; 33: 1597-604.

9. Cull A, Stewart M, Altman DG. Assessment of an intervention for psychosocial problems in routine oncology practice. Br J Cancer 1995; 72: 229-35.

10. Ford S, Lewis S, Fallowfield L. Psychological morbidity in newly referred patients with cancer. J Psychosom Res 1995; 39: 193-202.
11. Carroll BT, Kathol RG, Noyes R, Wald TG, Clamon GH. Screening for depression and anxiety in cancer patients using the hospital anxiety and depression scale. Gen Hosp Psychiatry 1993; 15: 69-74.

12. Jacobsen PB, Bovbjerg DH, Redd WH. Anticipatory anxiety in women receiving chemotherapy for breast cancer. Health Psychol 1993; 12: 469-75.

13. Fallowfield LJ, Hall A, Maguire GP, Baum M. Psychological outcomes of different treatment policies in women with early breast cancer outside a clinical trial. BMJ 1990; 301: 575-80.

14. Rhodes VA, Watson PM. Symptoms distress-the concept: past and present. Semin Oncol Nurs 1987; 3: 242-7.

15. Dodd MJ. Assessing patient self-care for side effects of cancer chemotherapy: Part 1 Cancer Nurs 1982; 5: 447-51.

16. Shapiro T. How to help patients through chemotherapy. Registered Nurse 1987; 50: 58-60.

17. Foot G. Needs assessment in tertiary and secondary oncology practice: A conceptual and methodological exposition $[\mathrm{PhD}$ dissertation]. Newcastle: University of Newcastle, 1996 (unpublished).

18. Spiegel D. Health caring: psychosocial support for patients with cancer. Cancer 1994; 74: 1453-7.

19. Meredith C, Symonds P, Webster L, Lamont D, Pyper E, Gillis CR, et al. Information needs of cancer patients in west Scotland: cross sectional survey of patients' views. BMJ 1996; 313: 724-6.

20. Foot G, Sanson-Fisher R. Measuring the unmet needs of people living with cancer. Cancer Forum 1995; 19: 131-5.

21. Harrison-Woermke DE, Graydon JE. Perceived informational needs of breast cancer patients receiving radiation therapy after excisional biopsy and axillary node dissection. Cancer Nurs 1993; 16: 449-55.

22. Gustafson DH, Taylor JO, Thompson S, Chesney P. Assessing the needs of breast cancer patients and their families. Quality Management in Health Care 1993; 2: 6-17.

23. Bonevski B, Sanson-Fisher R, Hersey P, Paul C, Foot G. Assessing the perceived needs of patients attending an outpatient melanoma clinic. J Psychosoc Oncol 1999; 17: 101-118.

24. Newell S, Sanson-Fisher R, Girgis A. The physical and psychosocial experiences of patients attending an outpatient medical oncology department: a cross-sectional study. Eur J Cancer Care 1999; 8: 73-82.

25. Youngblood M, Williams PD, Eyles H, Waring J, Runyon S. A comparison of two methods of assessing cancer therapyrelated symptoms. Cancer Nurs 1994; 7: 37-44.

26. Mor V, Allen SM, Siegel K, Houts P. Determinants of need and unmet need among cancer patients residing at home. Health Serv Res 1992; 27: 337-60.

27. Siegel K, Raveis VH, Houts P, Mor V. Caregiver burden and unmet patient needs. Cancer 1991; 68: 1131-40.

28. Guadagnoli E, Mor V. Daily living needs of cancer patients. $J$ Community Health 1991; 16: 37-47.

29. Bonevski B, Sanson-Fisher RW, Girgis A, Burton L, Cook P, Boyes A, et al. (The Supportive Care Review Group). Evaluation of an instrument to assess the needs of patients with cancer. Cancer 2000; 88(1): 217-225.

30. Sanson-Fisher R, Girgis A, Boyes A, Bonevski B, Burton L, Cook P et al. (The Supportive Care Review Group). The unmet supportive care needs of patients with cancer. Cancer 2000; 88(1): 226-237. 
31. Newell S, Sanson-Fisher RW, Girgis A, Bonaventura A. How Well Do Medical Oncologists' Perceptions Reflect Their Patients' Reported Physical and Psychosocial Problems? Cancer 1998; 83(8): 1640-1651.

32. Boyes A, Newell S, Girgis A, Sanson-Fisher RW. Improving the psychosocial care of cancer patients: effectiveness of printed feedback to oncologists (unpublished).
33. National Health and Medical Research Council (NHMRC) and National Breast Cancer Centre. Psychosocial clinical practice guidelines: information, support and counselling for women with breast cancer. Canberra: AGPS, 2000. W

\section{THE IMPORTANCE OF COMMUNICATION SKILLS TO EFFECTIVE CANCER CARE AND SUPPORT}

\author{
Phyllis Butow \\ Medical Psychology Research Unit \\ University of Sydney
}

In the last decade there has been an increasing emphasis on the teaching of communication skills. Why is this now considered so important, and does communication really influence patient outcomes in cancer care? The rationale for communication skills training in cancer care comes from a number of related points:

- good communication is a basic component of good clinical care, without which even the technical aspects of medicine cannot be effectively delivered;

- cancer carries with it a high psychological burden, thus the costs of poor communication are particularly salient in this patient population;

- the literature suggests there are currently substantial problems in doctor-patient communication;

- there is clear evidence that effective communication can make a difference to patient outcomes such as understanding and psychological adjustment;

- cancer patients place good communication high on their priorities for care;

- doctors regard their current training as inadequate, and cite communication difficulties as a major contributor to stress and burn-out;

- research has proven that communication skills can be taught and maintained.

This article presents the rationale for training in communication skills to be a priority for teams caring for cancer patients.

Kurtz, Silverman and Draper, in their text on teaching communication skills in medicine, state strongly that 'communication skills are not an optional extra in medical training; without appropriate communication skills, all our other clinical efforts can easily be wasted'. ${ }^{1}$ It has been estimated that doctors engage in 200,000 consultations in a professional lifetime, during which diagnoses are made, treatments are discussed, health care is delivered and patients' needs are assessed and met. Furthermore, numerous other interactions between members of the health team and patients involve communication at their core. The communication tasks in such interactions typically involve the gathering and delivery of information, and the provision of emotional support. Arguably, cancer patients have a particularly strong need for good communication in these domains.

Surveys of cancer patients show an increasing desire over time, especially among younger patients, to know everything about their cancer, and to be involved in making treatment decisions..$^{2-5}$ For example, over 90 per cent of patients in Lobb et al.'s study of patients with early stage breast cancer wanted to know their chance of being cured and the staging details of their cancer. ${ }^{2}$ In another Australian study, ${ }^{6}$ over 60 per cent of cancer patients seeing an oncologist for the first time indicated a preference for making a treatment decision either in collaboration with their doctor or on their own. Medical ethics has shifted from a paternalistic stance to one emphasising patient autonomy, with informed consent seen as the gold standard for achieving this end. However, informed consent requires much from both parties. Doctors are required to impart complex and potentially threatening information in a manner tailored to patient needs, provide a clear recommendation, and encourage a collaborative framework of decision-making. Such skills are not easily developed.

While a high standard of communication is often evidenced in cancer care, the literature suggests gaps and areas of particular difficulty. For example, while patients often report high satisfaction with overall care, Wiggers et al. reported much lower satisfaction (20-30 per cent) on items dealing with specific content areas and patient control. ${ }^{7}$ Patients were very dissatisfied with information about treatment benefits, side effects and symptom control, and about achieving a sense of control over their life. Complaints about the amount of information provided, the manner in which it is given, and its comprehensibility, were also commonly reported in a recent audit of hospital services in England. ${ }^{8}$ Indeed, the majority of malpractice allegations arise from a communication breakdown. ${ }^{9}$

Cancer patients also have high emotional needs. Prevalence rates for depression are reported as between 